\title{
SYNTHESIS OF NaP1 AND FAUJASITE ZEOLITE FROM NATURAL ZEOLITE OF ENDE-NTT AS LEAD (Pb(II))ADSORBENT
}

\author{
A.R. Utami, S. Sugiarti* and P. Sugita \\ Department of Chemistry, Bogor Agricultural University, Bogor, West Java, 16680, Indonesia \\ *E-mail: sri.sw07@gmail.com
}

\begin{abstract}
Synthesis of zeolite from Ende-Nusa Tenggara Timur (NTT) natural zeolite was conducted using the hydrothermal method, both with and without the addition of $\mathrm{Na}_{2} \mathrm{SiO}_{3}$ and $\mathrm{NaAlO}_{2}$. This research was conducted to produce synthetic zeolite utilized to remove lead $(\mathrm{Pb}(\mathrm{II}))$ through the adsorption process. The temperature of crystal formation (aging) was performed at $60^{\circ} \mathrm{C}$ for 6 hours, and the hydrothermal process was at $100^{\circ} \mathrm{C}$ for 24 hours. The resulting synthetic zeolite included the $\mathrm{NaP} 1$ and faujasite types. The effects of adsorption parameters, such as $\mathrm{pH}$ and contact time, were identified. The best adsorption capacity was demonstrated by synthetic zeolite without the addition of $\mathrm{Na}_{2} \mathrm{SiO}_{3}$ and $\mathrm{NaAlO}_{2}$, with a value of $144.7191 \mathrm{mg} / \mathrm{g}$ at $\mathrm{pH} 4$, with a45 minute contact time. The results showed that the synthesis of zeolite performed by the hydrothermal method could increase the cation exchange capacity (CEC) up to $105.42 \mathrm{cmol} / \mathrm{kg}$, from a natural zeolite with aCECof $20.14 \mathrm{cmol} / \mathrm{kg}$. The Langmuir model was consistent with an isothermal adsorption equilibrium process, and the adsorption free energy $\left(\Delta \mathrm{G}_{\text {ads }}\right)$ was consistent with physical adsorption (physisorption). The Nap1 zeolite of Ende-NTT natural zeolite was a better $\mathrm{Pb}(\mathrm{II})$ heavy metal adsorbent than the synthetic zeolites of fly ash and coal bottom ash.
\end{abstract}

Keywords: Adsorption, Adsorption Free Energy $\left(\Delta \mathrm{G}_{\mathrm{ads}}\right)$, CEC, Hydrothermal, Zeolite

@ ( RASĀYAN. All rights reserved

\section{INTRODUCTION}

Water pollution caused by heavy metals continues to be a major issue faced today. Heavy metals are dangerous pollutants in industrial process wastes from metallurgy, oil refining, pesticide production, paint, and battery industries ${ }^{1}$. The problem of pollutants, in forms of heavy metals, is more severe than that of organic pollutants due to the toxicity of heavy metal ions on organisms and the difficulty in dissolving them biologically and chemically. Lead $(\mathrm{Pb}(\mathrm{II}))$ is one of the problematic heavy metal pollutants.

A number of efforts have been made to reduce the concentration of toxic metals in the environment, one of which is by using the adsorption method. It is frequently chosen due to it's accessible, energy-efficient, and effectiveoperation ${ }^{2}$. One of the most commonly used adsorbents in waste treatment (of heavy metals like $\mathrm{Pb}(\mathrm{II})$ ) is natural zeolite ${ }^{3}$. The use of natural zeolite as an adsorbent is due to its simple method, raw material availability in nature, adequate adsorption capacity to control air and heavy metal pollution. In Indonesia, abundant natural zeolite is found and spread in several areas, one of which is in Ende-Nusa Tenggara Timur(NTT).

In general, natural zeolite has high $\mathrm{Si} / \mathrm{Al}$ ratios and contains impurities. These factors greatly reduce the Cation Exchange Capacity (CEC) and limit the application of natural zeolite ${ }^{4}$. Various efforts have been made to increase the adsorption capacity of natural zeolites, one of which is by using the hydrothermal method and changing the ratio of Si/Alin order to more closely resemble synthetic zeolites. Synthetic zeolites have high crystallinity and catalytic activity and contain minimum metal oxide impurities ${ }^{5}$. However, synthetic zeolites have high production $\operatorname{cost}^{6}$, and are not resistant tohightemperature ${ }^{7}$. Meanwhile, natural zeolites have low crystallinity and catalytic activity as they contain a large number of metal oxide impurities, and diverse pore sizes $^{8}$, but have good thermal stability ${ }^{9}$. A large Si/Al ratio value Rasayan J. Chem., 12(2), 650-658(2019) http://dx.doi.org/10.31788/RJC.2019.1222056

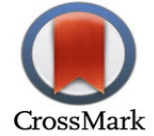


indicates positive charge and results in smaller cation exchange capacity of a zeolite, while a small Si/Al ratio indicates a negative charge and a greater cation exchange capacity of a zeolite ${ }^{10}$.

This research conducted a synthesis of zeolite from Ende-NTT natural zeolite by using the hydrothermal method with varied concentrations of $\mathrm{Na}_{2} \mathrm{SiO}_{3}$ and $\mathrm{NaAlO}_{2}$. In addition, in accordance with the increased adsorption capacity of methylene blue from synthetic zeolites resulting in an increase in adsorption capacity by $46.7 \%$ and CEC by $16 \%{ }^{11}$, tests were conducted to observe the effects of produced synthetic zeolite on $\mathrm{Pb}(\mathrm{II})$ heavy metal adsorption.

\section{Natural Zeolite Preparation and Activation}

\section{EXPERIMENTAL}

The natural zeolites were ground and sieved into powder with the required sieve size of 200Meshand heated in a $300{ }^{\circ} \mathrm{C}$ furnace for 3 hours, to give unactivated natural zeolite (Z). Furthermore, they were chemically activated by mixing in $3 \mathrm{M} \mathrm{HCl}$ and $3 \mathrm{M} \mathrm{NaOH}$ solutions, to give activated natural zeolite ZA and $\mathrm{ZB}$, respectively. Then, the natural zeolites, both before and after activation, were further characterized by XRD, SEM, and FTIR.

\section{The Synthesis of Zeolite Using Hydrothermal Method with or without the Addition of $\mathrm{Na}_{2} \mathrm{SiO}_{3}$ and $\mathrm{NaAlO}_{2}$}

Unactivated natural zeolite $(Z)$ samples with a total weight of 7 grams were added with $25 \mathrm{~mL}$ of $2 \mathrm{M}, 2.5$ $\mathrm{M}, 3 \mathrm{M}$, and $3.5 \mathrm{M} \mathrm{NaOH}$. The aging process consisted of heating the mixtures at $60^{\circ} \mathrm{C}$ for 6 hours, to initiate the process of crystalline nuclei formation. Then the hydrothermal process consisted of heating the mixtures at $100^{\circ} \mathrm{C}$ for 24 hours. After hydrothermal treatment, the crystallized solids were characterized by XRD to identify the sample conditions and optimum $\mathrm{NaOH}$ concentration for the hydrothermal synthesis process. The same procedure was done for base and acid activated zeolite.

The reaction condition that yielded a synthetic zeolite with the highest crystallinity value was then used in the synthesis of zeolite with the addition of silicate and aluminate. In this case, the best result was shown by base-activated zeolite $(\mathrm{ZB})$ with the concentration of $\mathrm{NaOH}$ of $3 \mathrm{M}$. The above procedure then repeated by reacting $\mathrm{ZB}$ with the addition of $\mathrm{Na}_{2} \mathrm{SiO}_{3}$ or $\mathrm{NaAlO}_{2}$, and $3 \mathrm{M}$ of $\mathrm{NaOH}$. After the hydrothermal treatment, the crystallized solids of synthetic zeolites, ZS (from unactivated zeolite), ZSA (from acidactivated zeolite), and ZSB (from base-activated zeolite), were characterized by XRD, SEM, and FTIR.

\section{Determination of Lead (II) Optimum Adsorption Parameters}

A total of 0.05 grams of zeolite adsorbent was mixed with $50 \mathrm{~mL}$ of $\mathrm{Pb}$ (II) solution at a concentration of $200 \mathrm{mg} / \mathrm{L}$. The mixture was shaken, and subsequently, the mixture was centrifuged for 15 minutes, and the $\mathrm{Pb}$ (II) content in the filtrate was analyzed by using AAS. The adsorption was observed based on two parameters, $\mathrm{pH}$ and contact time. The $\mathrm{pH}$ of $\mathrm{Pb}$ (II) solutions used was 2,4 , and 6 . While the contact time applied was $15,30,45,60,75,90,105,120$, and 135 minutes. To maintain the $\mathrm{pH}$ of the solutions, $0.1 \mathrm{M}$ $\mathrm{NaOH}$ or $0.1 \mathrm{M} \mathrm{HNO}_{3}$ was added before the adsorption.

\section{CEC (Cation Exchange Capacity) Determination}

A total of 0.1 grams of zeolite was added to $10 \mathrm{~mL}$ of $0.5 \mathrm{M} \mathrm{CaCl}_{2}$ solution and saturated for 24 hours. The solution was separated by centrifugation for 15 minutes. The supernatant was removed, and the pellets were then washed using $80 \%$ ethanol until chloride free. The chloride-free pellets were further extracted to obtain the calcium absorbed in the zeolite samples. The extraction was performed using 10 $\mathrm{mL}$ of $1 \mathrm{M} \mathrm{NH}_{4} \mathrm{Cl}$ for one hour. The extraction process was repeated for 5 times. The collected extract was then mixed with $1 \mathrm{M} \mathrm{NH}_{4} \mathrm{Cl}$ up to $100 \mathrm{~mL}$ of volume. Then the calcium was measured using AAS.

\section{Determination of Adsorption Isotherm}

A total of 0.05 grams of zeolite adsorbent was added to $50 \mathrm{~mL}$ of $\mathrm{Pb}(\mathrm{II})$ solution at concentrations of 100 , $150,200,250,300,350$, and $400 \mathrm{mg} / \mathrm{L}$ at the optimum $\mathrm{pH}$ and then agitated using the optimum contact time. Subsequently, the mixtures were centrifuged for 15 minutes, and the $\mathrm{Pb}$ (II) content in the filtrates was analyzed using AAS.

\section{RESULTS AND DISCUSSIONS}

The results of XRD analysis conducted on Ende-NTT natural zeolite (Z)are shown in Fig.-1. The figure highlights that the natural zeolite is mixture of mordenite and clinoptilolite zeolites as they have 
characteristic peaks at the angle of $2 \theta$ in accordance with JCPDS database. The activation treatment in this study was conducted chemically by adding $3 \mathrm{M} \mathrm{NaOH}$ (base activation) and $3 \mathrm{M} \mathrm{HCl}$ (acid activation). The activation of the natural zeolite aimed to remove the impurities. The results of XRD analysis conducted on Ende-NTT natural zeolite after the activation process are shown in Fig.-1. Figure-1 indicates that the activation treatment with $3 \mathrm{M} \mathrm{NaOH}$ and $3 \mathrm{M} \mathrm{HCl}$ did not significantly change the diffractogram peak due to the relatively stable natural zeolite structure because the natural zeolites contain a high amount of metal oxides providing resistance in the basic structure of the zeolite ${ }^{11}$.

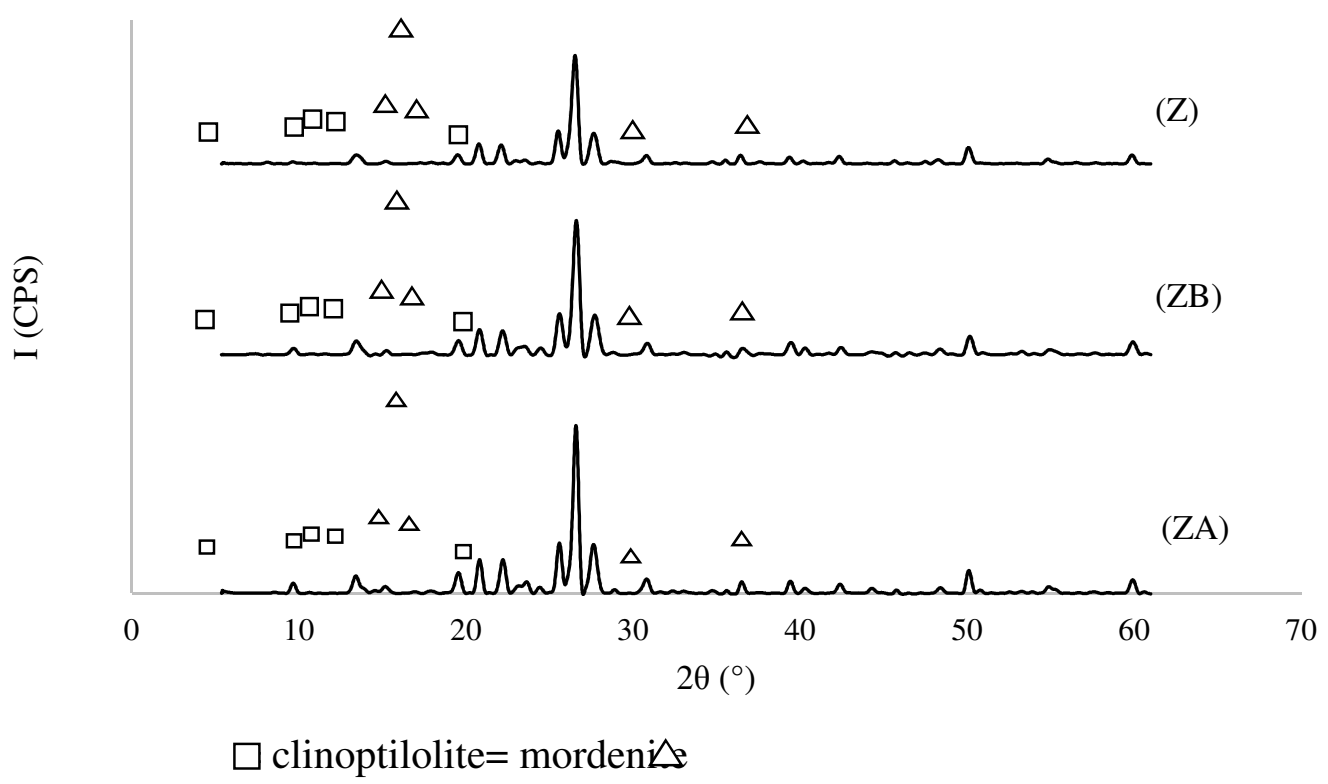

Fig.-1: Diffractogram of Ende-NTT Inactivate Natural Zeolite (Z), $3 \mathrm{M} \mathrm{NaOH}$ Activation (ZB), and $3 \mathrm{M} \mathrm{HCl}$ Activation $(\mathrm{ZA})$

$\mathrm{NaOH}$ acts as a dissolving activator for the $\mathrm{Si}$ and $\mathrm{Al}$ contained in the zeolite samples. $\mathrm{Na}^{+}$cations also holds an important role in zeolitization in which the production of water-soluble sodium silicate is higher, so that the crystallizing process in synthetic zeolite formation becomes faster ${ }^{12}$. The hydrothermal method aimed to produce zeolites with high purity and good thermal properties more resistant to heat. The crystallinity of the synthetic zeolites at various concentrations of $\mathrm{NaOH}$ is shown in Table-1. Table-1 shows that the optimum $\mathrm{NaOH}$ concentration for the synthesis of zeolite by the hydrothermal method is 3 $\mathrm{M}$ in zeolites with base activation (3 M ZSB), as they have the highest crystallinity degree of $64.66 \%$. The high degree of crystallinity evidenced in the $3 \mathrm{M}$ ZSB (ZSB0) zeolite sample, which was synthesized with $3 \mathrm{M} \mathrm{NaOH}$, indicates that its structure is more organized than other zeolite samples.

Table-1: Crystallinity of Synthetic Zeolites on varied $\mathrm{NaOH}$ Concentrations

\begin{tabular}{c|c}
\hline Sample & Crystallinity Degree (\%) \\
\hline 2 M ZS (2 M NaOH) & 56.9 \\
\hline 3 M ZS (3 M NaOH) & 53.06 \\
\hline 2 M ZSA $(2 \mathrm{M} \mathrm{NaOH})$ & 63.21 \\
\hline $3 \mathrm{M} \mathrm{ZSA}(3 \mathrm{M} \mathrm{NaOH})$ & 63.87 \\
\hline 2 M ZSB $(2 \mathrm{M} \mathrm{NaOH})$ & 63.54 \\
\hline 3 ZSB / ZSB0 $(3 \mathrm{M} \mathrm{NaOH})$ & 64.66 \\
\hline $3.5 \mathrm{M} \mathrm{ZSB}(3.5 \mathrm{M} \mathrm{NaOH})$ & 59.92 \\
\hline
\end{tabular}

The synthesis process of zeolites by adding different amounts of $\mathrm{Na}_{2} \mathrm{SiO}_{3}$ and $\mathrm{NaAlO}_{2}$ was conducted using the synthesis conditions for ZSB0 synthesized with $3 \mathrm{M} \mathrm{NaOH} . \mathrm{Na}_{2} \mathrm{SiO}_{3}$ and $\mathrm{NaAlO}_{2}$ were added to 
provide other sources of silica and alumina; thus, eventually changing the $\mathrm{Si} / \mathrm{Al}$ ratio of the zeolite products. The results of XRD analysis performed on the synthesized zeolites by the hydrothermal method of Ende-NTT natural zeolite, either with or without the addition of $\mathrm{Na}_{2} \mathrm{SiO}_{3}$, and $\mathrm{NaAlO}_{2}$ are shown in Fig.-2. Figure-2 shows that the synthetic zeolites of ZSB0, ZSBSi10, ZSBSi20, ZSBA110, and ZSBAl20 are mixtures of $\mathrm{NaP} 1$ and faujasite types of zeolites as they have characteristic peaks at the angle of $2 \theta$ in accordance with the JCPDS database. The best-synthesized zeolite with the addition of $\mathrm{Na}_{2} \mathrm{SiO}_{3}$ and $\mathrm{NaAlO}_{2}$ variation was the one from the addition of $20 \mathrm{~mL} \mathrm{Na} \mathrm{SiO}_{3}(\mathrm{ZBSi} 20)$ due to its highest percent crystallinity of $75.11 \%$. Figure- 2 also shows that ZBSi20 is dominated by faujasite type zeolite. Addition of silicate resulted in more dominate faujasite-type zeolite, as shown by the increase of the intensity of peak at $2 \theta\left({ }^{\circ}\right)$ of 26.6677. In contrast, the addition of aluminate resulted in a more dominate NaP1 type zeolite, as shown by a peak at $2 \theta\left(^{\circ}\right)$ of 28.0813 .

The results of SEM analysis performed on Z and ZSBSi20 are shown in Fig.-3. Figure-3a shows the morphology of the natural zeolite, a mixture of mordenite and clinoptilolite. The zeolite was not in a granule form, instead, the two types zeolite were attached. Figure-3b also shows a mixture of zeolites $\mathrm{NaP} 1$ and faujasite. The NaP1 looks more like thin plates stuck together in granules, while the faujasite had ortho rhombic structure. Faujasite consist of two types of zeolite, the $\mathrm{X}$ and $\mathrm{Y}$ types of zeolite, with $\mathrm{Si} / \mathrm{Al}$ ratio of 1-1.5 and 2.5, respectively ${ }^{13}$. Meanwhile, the NaP1 has the Si/Al ratio of around 2.3 $3^{14}$.

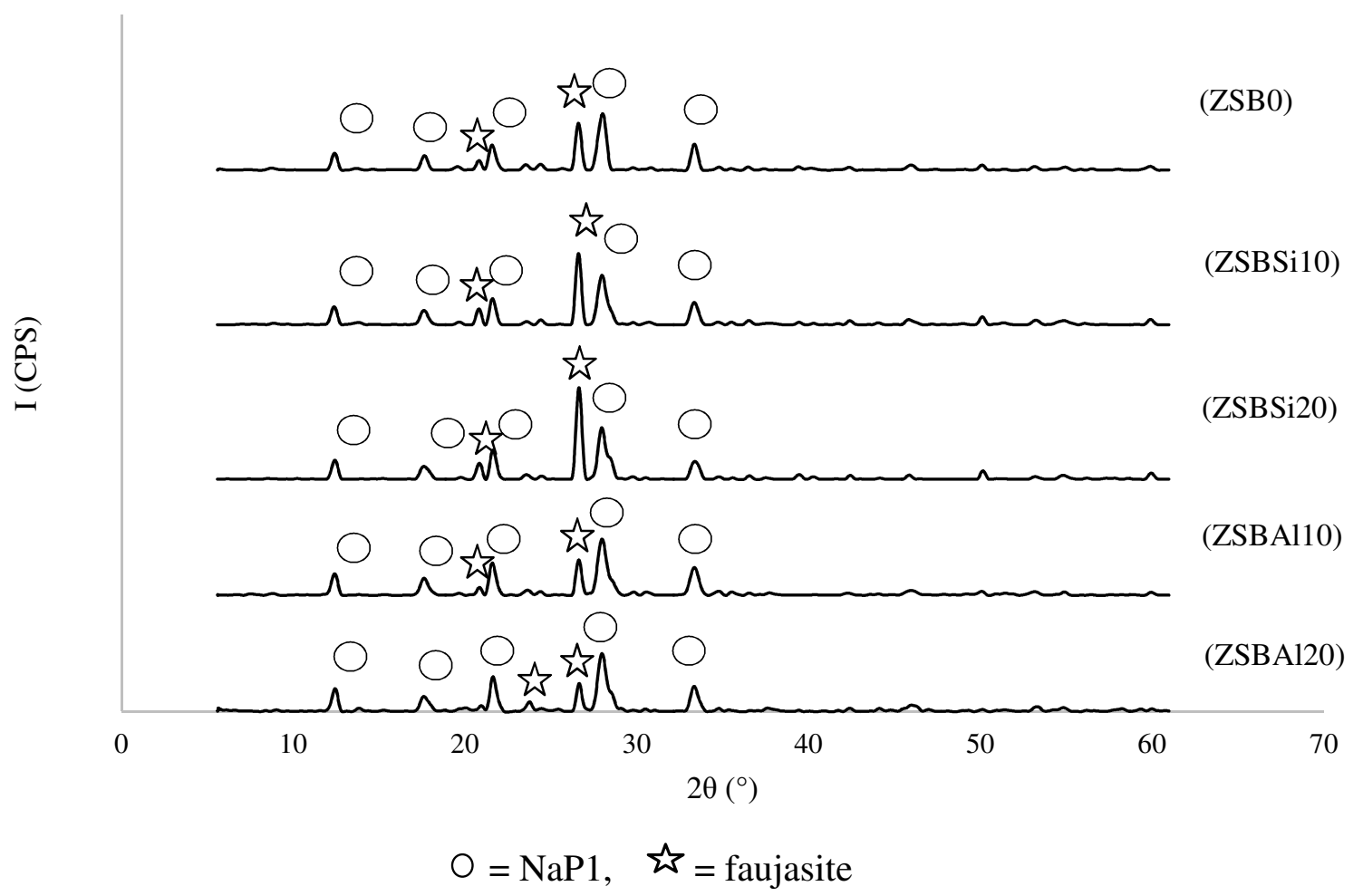

Fig.-2: Diffractogram of Synthetic Zeolite without the Addition of $\mathrm{Na}_{2} \mathrm{SiO}_{3}$ and $\mathrm{NaAlO}_{2}$ (ZSB0), with Additions of $10 \mathrm{~mL} \mathrm{Na}_{2} \mathrm{SiO}_{3}$ (ZSBSi10), $20 \mathrm{~mL} \mathrm{Na} 2 \mathrm{SiO}_{3}$ (ZSBSi20), $10 \mathrm{~mL} \mathrm{NaAlO} 2$ (ZSBAl10), and $20 \mathrm{~mL} \mathrm{Na} 2 \mathrm{SiO}_{\mathrm{s}}(\mathrm{ZSBAl} 20)$

FTIR spectrum analysis was performed to identify the functional groups in the natural and synthetic zeolites. The results of the Z, ZSB0, and ZSBSi20 FTIR are shown in Fig.-4. It shows that the range of O$\mathrm{Al}-\mathrm{O}$ or O-Si-O symmetry on the internal tetrahedral structure of the Z, ZSB0, and ZSBSi20 appeared respectively in bands at 693, 694, and $694 \mathrm{~cm}^{-1}$, while for external linkages appeared respectively in bands at 796, 778, and $778 \mathrm{~cm}^{-1}$. Si-O or Al-O folds in the Z, ZSB0, and ZBSi20 appeared respectively in bands at 461, 436, and $441 \mathrm{~cm}^{-1}$, while the asymmetric range of $\mathrm{Z}, \mathrm{ZSB} 0$, and ZBSi20 appeared respectively in bands at 1041, 1015, and $1029 \mathrm{~cm}^{-1}$. The synthesis process either with or without the addition of $\mathrm{Na}_{2} \mathrm{SiO}_{3}$ and $\mathrm{NaAlO}_{2}$ had no effect on the functional groups of the zeolites as the synthetic 
zeolite absorption band is still located in the main area of the tetrahedral bonds of the main zeolite components $\left(\mathrm{SiO}_{4}{ }^{4-}\right.$ and $\left.\mathrm{AlO}_{4}{ }^{5-}\right)$ include the band emergence in the symmetry range of O-Al-O or O-Si-O in the internal tetrahedral region at $650-720 \mathrm{~cm}^{-1}$; while for the external linkage, the band will appear in the region at $750-820 \mathrm{~cm}^{-1}$. The symmetric-O or Al-O will appear in the region of $420-500 \mathrm{~cm}^{-1}$, while absorption in the region of $950-1250 \mathrm{~cm}^{-1}$ indicates an asymmetric range ${ }^{15}$.

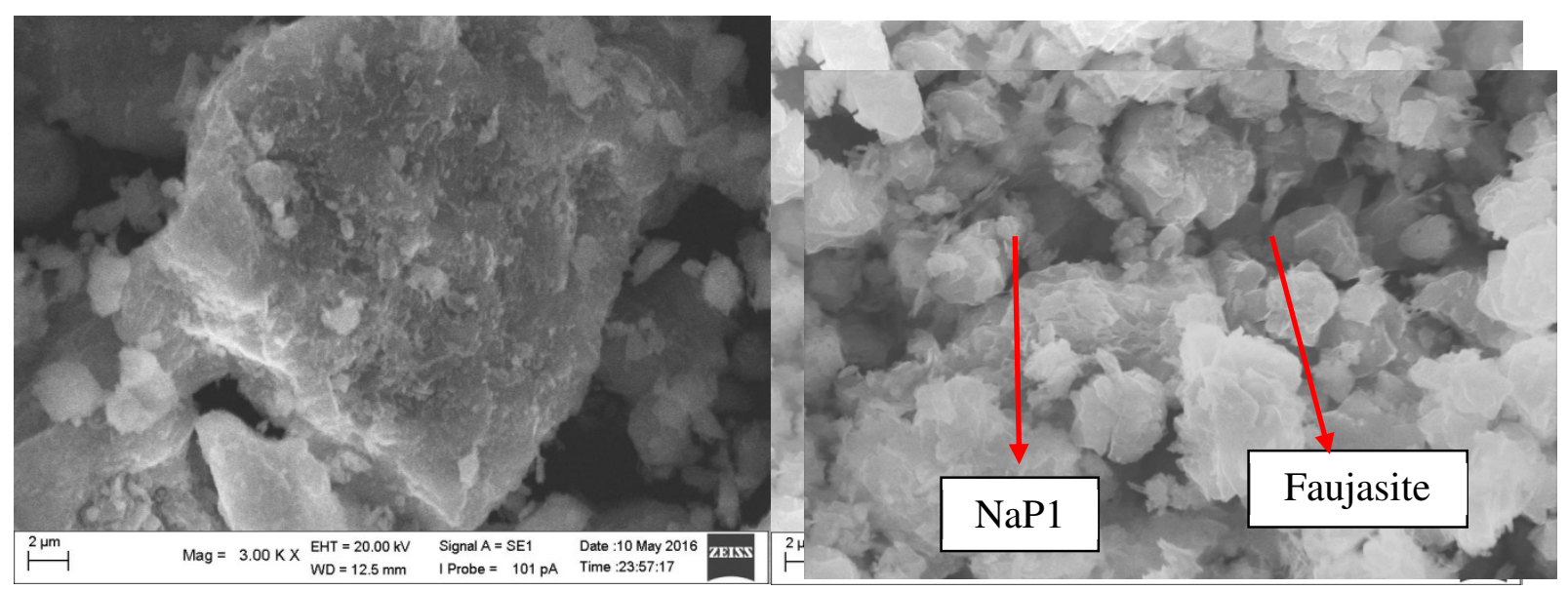

(a)

(b)

Fig.-3: Surface Morphology of ZA (a) and ZSBSi20 (b)

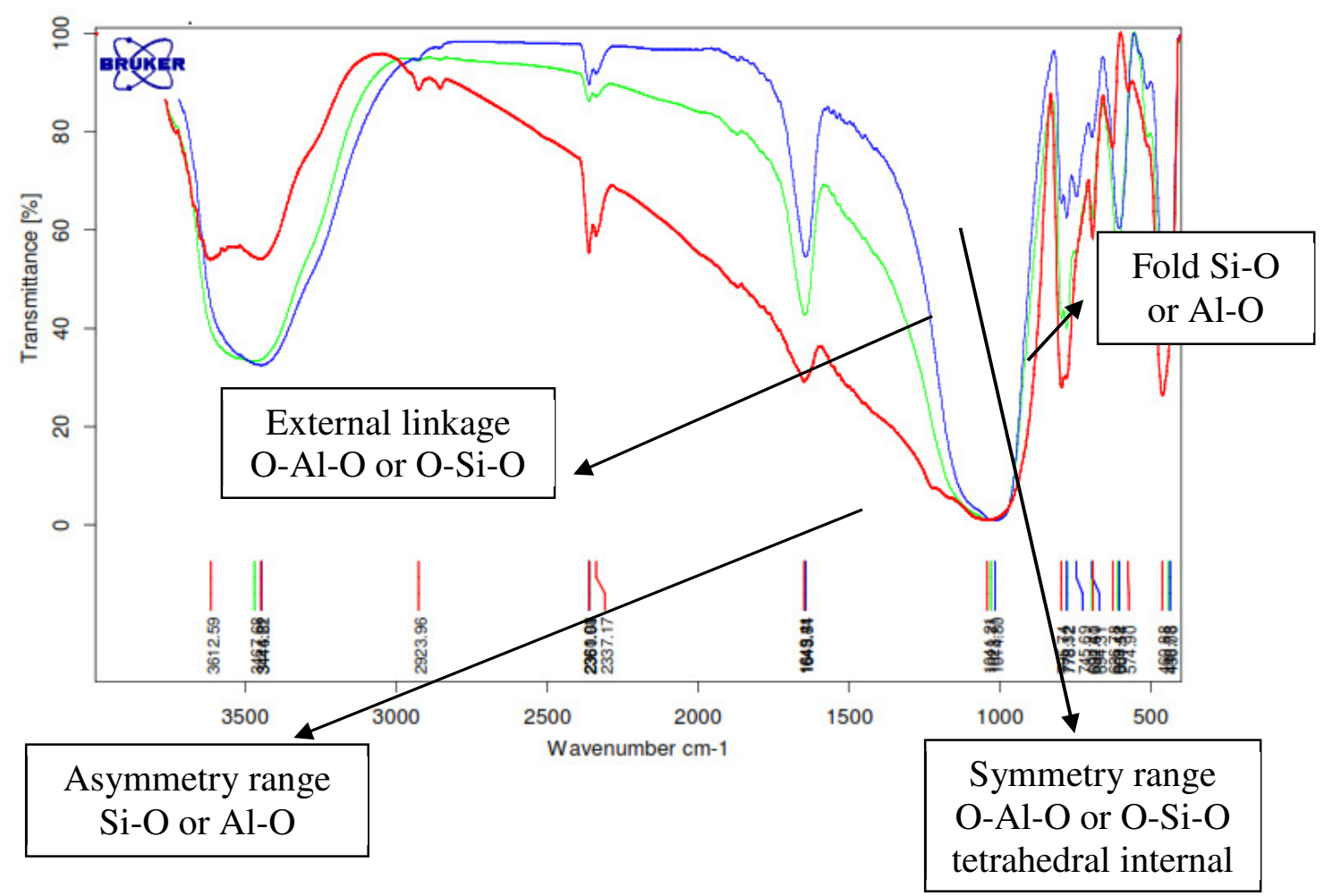

Fig.-4: Spectrum of FTIR Z $(\square), Z S B 0(-)$, and ZSBSi20 $(\square)$

Optimization of adsorption parameters of $\mathrm{Pb}$ (II) metal ion by ZSB0 and ZSBSi20 adsorbents were performed by varying $\mathrm{pH}$ and contact time. The optimum $\mathrm{pH}$ for $\mathrm{ZSB} 0$ and $\mathrm{ZSBSi} 20$ adsorbents in $\mathrm{Pb}$ (II) metal ions adsorption occurred at $\mathrm{pH} 4$ with respective adsorption capacities of 124.4064 and 90.3279 
mg/g (Fig.-5). Meanwhile, the optimum contact time for ZSB0 and ZSBSi20 adsorbents was 45 and 105 minutes with respective adsorption capacities of 144.7191 and $125.1530 \mathrm{mg} / \mathrm{g}$ (Fig.-6a and 6b). This result is better than the adsorption of $\mathrm{Pb}$ (II) metal ions by using NaP1 zeolite from fly ash with a maximum adsorption capacity of $0.98 \mathrm{mg} / \mathrm{g}^{16}$ and $\mathrm{NaP} 1$ zeolite from coal bottom ash with a maximum adsorption capacity of $15.4 \mathrm{mg} / \mathrm{g}^{17}$.

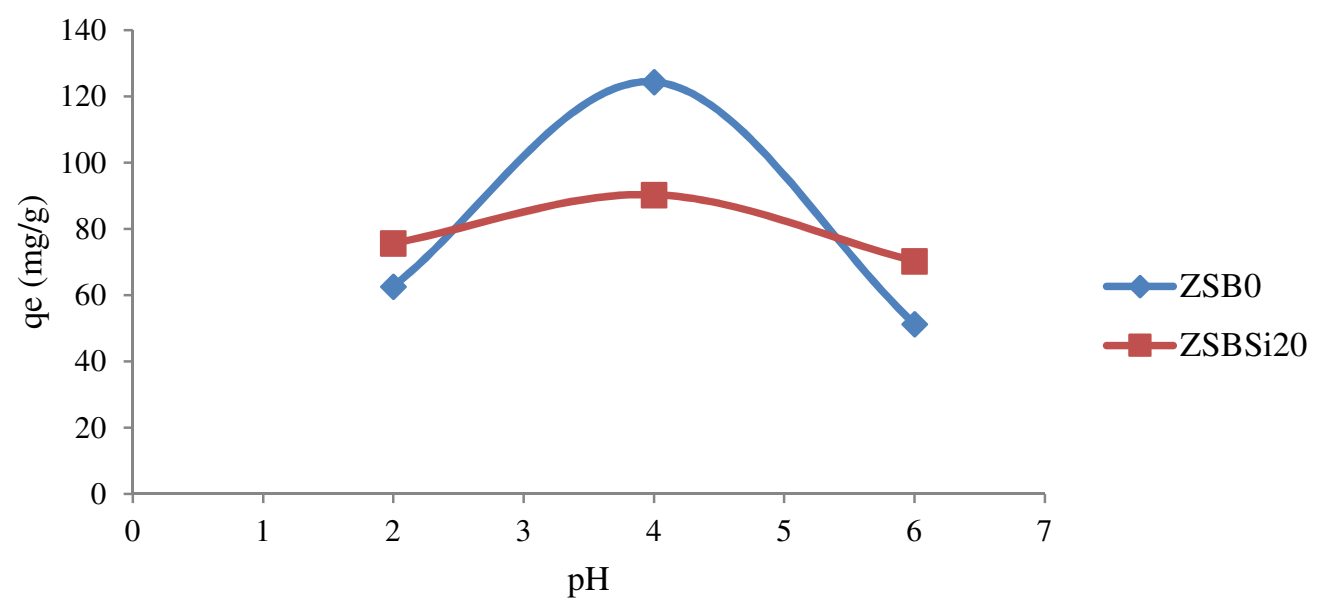

Fig.-5: Adsorption Capacity of ZSB0 and ZSBSi20 on Pb(II) Metal Ion at varied pH
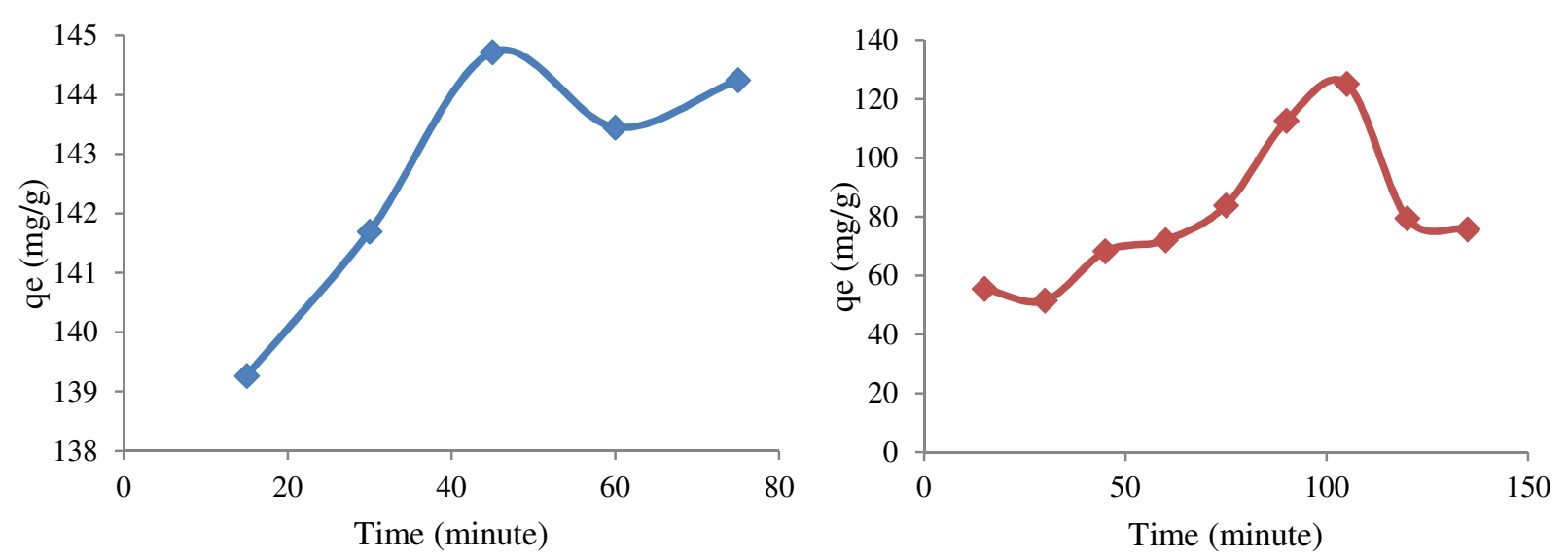

(a) (b)

Fig.-6: Adsorption Capacity of ZSB0(a) and ZSBSi20 (b) on Pb(II) Metal Ion at varied Contact Time

One common indicator to identify the quality of zeolites before and after the synthesis process is to measure the ion exchange capacity, known as CEC. The CEC of natural zeolite and synthetic zeolite is shown in Fig.-7. Figure-7 shows that the process of chemical zeolite activation and hydrothermal synthesis can increase CEC. The increase of CEC through the activation process and hydrothermal synthesis caused by this treatment has cleared the zeolite pore space of water molecules and metal oxides, as well as produced zeolite with high crystallinity enabling zeolite activity to increase ${ }^{18}$. In addition to the removal of the metal oxides covering the exchange area and increasing the pore size, the hydrothermal synthesis process can also lead to the transformation process of natural zeolite into a type of synthetic zeolite with better quality ${ }^{19}$.

The determination of adsorption isotherm was performed to determine the relationship between adsorbate concentration and absorption rate at the adsorbent surface at room temperature and optimum condition, as well as the interaction between adsorbent and adsorbate. The data results of $\mathrm{Pb}(\mathrm{II})$ metal ion isotherm 
adsorption by ZSB0 and ZSBSi20 were analyzed by using two adsorption isotherm models: the Langmuir and Freundlich models.

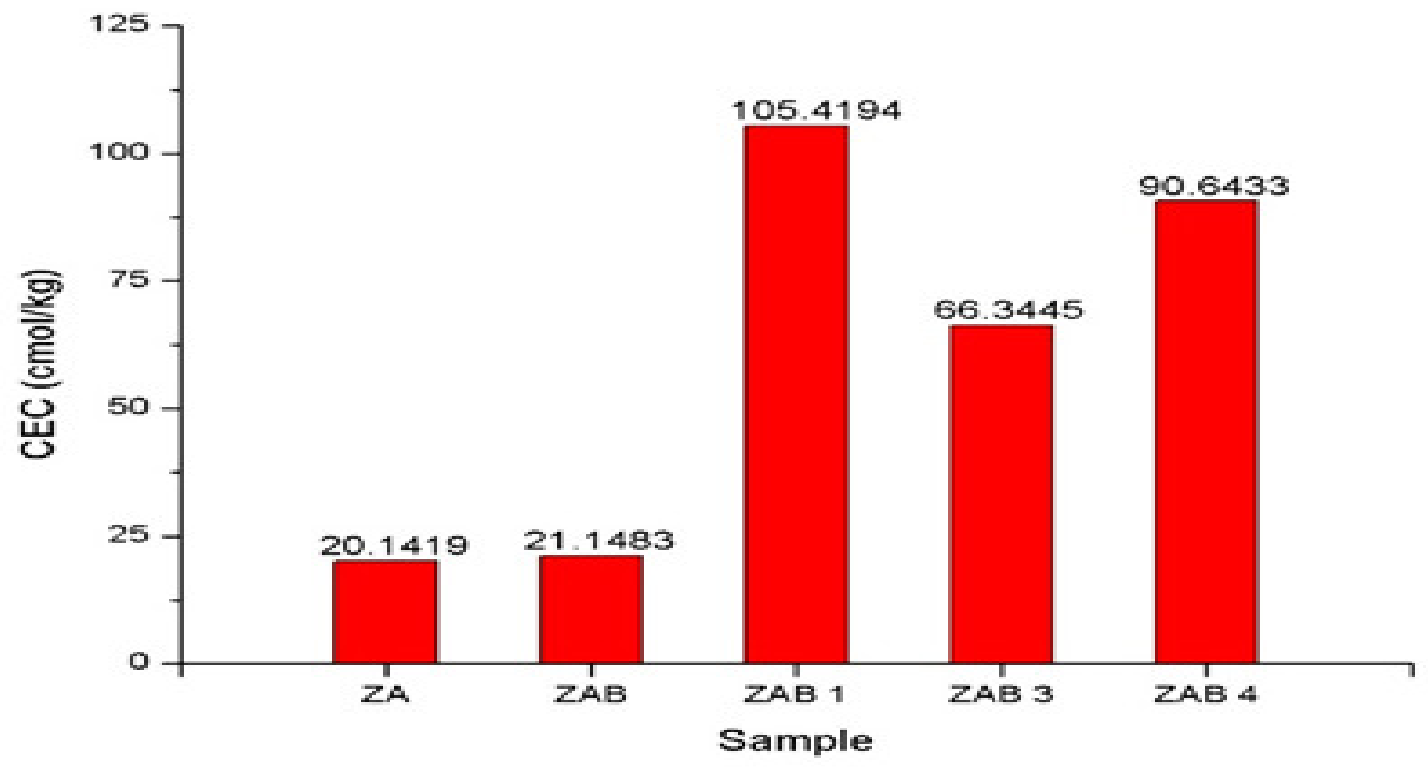

Fig.-7: Natural Zeolite and Synthetic Zeolite CEC

Based on the linear equations obtained from the Langmuir and Freundlich isotherm adsorption curves, the values of isotherm parameters including $\mathrm{R}^{2}, \mathrm{qm}, \mathrm{K}_{\mathrm{L}}, \mathrm{R}_{\mathrm{L}}, \mathrm{K}_{\mathrm{F}}$, and $\mathrm{n}$ were determined. The isotherm parameter values of $\mathrm{Pb}$ (II) metal ion adsorption by ZSB0 and ZSBSi20 are shown in Table- 2 .

Table-2: Adsorption Isotherm Parameter of Pb(II) Metal Ion by ZSB0 and ZSBSi20

\begin{tabular}{c|c|c|c}
\hline Isotherm & Parameter & ZSB0 & ZSBSi20 \\
\hline Langmuir & $\mathrm{R}^{2}$ & 0.9494 & 0.9925 \\
\hline & $\mathrm{qm}$ & 181.8181 & 85.4701 \\
\hline & $\mathrm{K}_{\mathrm{L}}$ & 0.7639 & 0.3939 \\
\hline & $\mathrm{R}_{\mathrm{L}}$ & 0.0129 & 0.0247 \\
\hline Freundlich & $\mathrm{R}^{2}$ & 0.7088 & 0.6461 \\
\hline & $\mathrm{K}_{\mathrm{F}}$ & 79.5976 & 47.2933 \\
\hline & $\mathrm{n}$ & 0.2052 & 0.1211 \\
\hline
\end{tabular}

Table-2 highlights the adsorption of $\mathrm{Pb}$ (II) metal ions by ZSB0 and ZSBSi20 entailing the Langmuir isotherm model, for it provides a fairly high correlation coefficient $\left(\mathrm{R}^{2}\right)$ respectively of 0.9494 and 0.9925 , followed by the Freundlich isotherms respectively of 0.7088 and 0.6461 . This shows that the adsorption process is dominated by monolayer adsorption (homogeneous). The Langmuir isotherm describes adsorption on one active side in which once a molecule occupies an active site, there will be no further absorption, and if the adsorbent active site is saturated with adsorbate, increased adsorbate concentration does not elevate the amount of adsorbed $\mathrm{Pb}$ (II) metal ions ${ }^{20}$.

Other parameters utilized to determine the adsorption process were the values of $q \mathrm{~m}, \mathrm{~K}_{\mathrm{L}}$, and $\mathrm{R}_{\mathrm{L}}$. The qm value represents the maximum theoretical adsorption capacity. $\mathrm{K}_{\mathrm{L}}$ value indicates the capacity of the adsorbate molecular bond on the adsorbent. The value of $\mathrm{R}_{\mathrm{L}}$ is an equilibrium parameter or an adsorption dimension stating that $R_{L}>1$ value indicates poor adsorption process, $R_{L}=1$ value indicates the linear adsorption process, $0<\mathrm{R}_{\mathrm{L}}<1$ value indicates beneficial adsorption process, and $\mathrm{R}_{\mathrm{L}}=0$ indicates that the adsorption process is irreversible ${ }^{21}$. Table-2 shows the $\mathrm{qm}$ and $\mathrm{K}_{\mathrm{L}}$ values in ZSB0werehigher than in ZSBSi20, whereas the $\mathrm{R}_{\mathrm{L}}$ values of ZSB0 and ZSBSi20 were in the range of $0<\mathrm{R}_{\mathrm{L}}<1$. This indicates that 
the ZSB0adsorbent is better for use as a $\mathrm{Pb}(\mathrm{II})$ metal ion adsorbent compared with the ZSBSi20 adsorbent.

The value of adsorption-free energy $\left(\Delta \mathrm{G}_{\mathrm{ads}}\right)$ was also examined to determine the nature of the adsorption process. The values of $\Delta \mathrm{G}_{\text {ads }}$ up to $-20 \mathrm{~kJ} / \mathrm{mol}$ are consistent with physical adsorption (physisorption), whereas $\Delta \mathrm{G}_{\text {ads }}$ values above $-40 \mathrm{~kJ} / \mathrm{mol}$ are consistent with chemical adsorption (chemisorption) ${ }^{22}$. The results of $\Delta \mathrm{G}_{\mathrm{ads}}$ calculation in this research showed that the value of $\Delta \mathrm{G}_{\mathrm{ads}}$ for ZSB0 samples is -9.0874 $\mathrm{kJ} / \mathrm{mol}$, and that for ZSBSi20 samples is $-7.6464 \mathrm{~kJ} / \mathrm{mol}$. Hence, the ZSB0and ZSBSi20adsorbents in $\mathrm{Pb}$ (II) metal ions adsorption have physical adsorption properties (physisorption).

Physical adsorption (physisorption) occurs when the intermolecular force is greater than the attraction force between the molecules or the relatively weak attraction force between the adsorbate and the adsorbent surface. This force is called the Vander Waals force, so that the adsorbate can move from one surface to another part of the adsorbent ${ }^{23}$. The force between molecules is the attraction between the fluid molecules and the solid surface, while the intermolecular force is the attraction among the fluid molecules.

\section{CONCLUSION}

The synthesis process succeeded in producing NaP1 and faujasite types of synthetic zeolites. The two best synthetic zeolites, ZSB0 and ZSBSi20, were used in the adsorption of $\mathrm{Pb}$ (II) metal ion. The optimum conditions for the $\mathrm{Pb}(\mathrm{II})$ metal ion adsorption by theZSB0 was obtained at $\mathrm{pH} 4$ for 45 minutes, which is more efficient compared to the ZSBSi20. The synthetic zeolites were shown to have higher CEC than the natural zeolite. The adsorption process of $\mathrm{Pb}$ (II) metal ions by the synthetic zeolites ZSB0 and ZSBSi20 followed the Langmuir isotherm model and had physical adsorption properties (physisorption).

\section{REFERENCES}

1. H. L. Yadav and A. Jamal, Rasayan Journal of Chemistry, 10(3), 1062(2017), DOI: 10.7324/RJC.2017.1031781

2. P. Panneerselvam, N. Thinakaran, K. V. Thiruvenkataravi, M. Palanichamy, and S. Sivanesan, Journal of Hazardous Materials, 159(2-3), 427(2008), DOI: 10.1016/j.jhazmat.2008.02.033

3. K. B. Payne and T. M. Abdel-Fattah, Jounal of Environmental Science and Health Part A. Toxic/Hazardous Substances and Environmental Engineering, A39(9), 2275(2004), DOI: 10.1081/LESA-200026265

4. Y. Wang and F. Lin, Journal of Hazardous Materials, 166(2-3), 1014(2009), DOI: 10.1016/j.jhazmat.2008.12.001

5. W. Chaikittisilp, K. Muraoka, Q. Ji, K. Ariga, and Y. Yamauchi, Journal of Material Chemistry A, 2(31), 12096(2014), DOI: 10.1039/C3TA15389D

6. W. Aguilar-Mamani, G. Garcia, J. Hedlund, and J. Mouzon, Springerplus, 3, 292(2014), DOI: 10.1186/2193-1801-3-292

7. A. D. Fazio, P. Brotzu, M. R. Ghiara, M.L. Fercia, R. Lonis, and A. Sau, Periodico di Mineralogia, 77, 79(2008), DOI: $10.2451 / 2008$ PM0006

8. M.W. Ackley, S.U. Rege, and H. Saxena, Microporous and Mesoporous Materials, 61, 25(2002), DOI: $10.1016 /$ S1387-1811(03)00353-6

9. G. Cruciani, Journal of Physics and Chemistry of Solids, 67, 1973(2006), DOI: 10.1016/j.jpcs.2006.05.057

10. S. Wang, and Y. Peng, Chemical Engineering Journal, 156, 11(2010), DOI: 10.1016/j.cej.2009.10.029

11. Y. D. Ngapa, S. Sugiarti, and Z. Abidin, Indonesian Journal of Chemistry, 16(2), 138(2016), DOI: 10.22146/ijc. 21156

12. C. A. Ríos, C. D. Williams, and O. M. Castellanos, Ingeniería y Competitividad, 14(1), 9(2012), DOI: $10.25100 /$ iyc.v14i2.2661

13. D. Verboekend, N. Nuttens, R. Locus, J. V. Aelst, P. Verolme, J.C. Groen, J. P. Ramirez, and B. F. Sels, Chemical Society Reviews, 45(12), 3331(2016), DOI: 10.1039/c5cs00520e

14. A. Woszuk, A. Zofka, L. Bandura, and W. Franus, Construction and Building Materials, 139, 247(2017), DOI: 10.1016/j.conbuildmat.2017.02.054 
RASĀYAN J. Chem.

Vol. 12 | No. 2 |650 - 658| April - June | 2019

15. C. Che,T. D. Glotch, D. L. Bish, J. R. Michalski, and W. Xu, Journal of Geophysical Research E: Planets, 116, E05007(2011), DOI:10.1029/2010JE003740

16. W. Yanxin, G. Yonglong, Y. Zhihua, C. Hesheng, and X. Querol, Science in China Series D Earth Sciences, 46(9), 967(2003), DOI: 10.1360/02yd0487

17. N. I. Um, G. C. Han, K. S. You, and J. W. Ahn, Resources Processing, 56, 130(2009), DOI: 10.4144/rpsj.56.130

18. M. Tatlier, G. Munz, G. Fueldner, and S. K. Henninger, Microporous and Mesoporous Materials, 193, 115(2014), DOI: 10.1016/j.micromeso.2014.03.017

19. Y. Watanabe, H. Yamada, J. Tanaka, and Y. Moriyoshi, Journal of Chemical Technology and Biotechnology, 80, 376(2005), DOI: 10.1002/jctb.1224

20. M. Rasouli, N. Yaghobi, M. Hafezi, and M. Rasouli, Journal of Industrial and Engineering Chemistry, 18(6), 1970(2012), DOI: 10.1016/j.jiec.2012.05.014

21. C. Meziti, and A. Boukerroui, Procedia Engineering, 33, 303(2009), DOI: 10.1016/j.proeng.2012.01.1208

22. A. A. Khadomi, A.S. Yaro, and A. A. H. Kadhum, Journal of the Chilean Chemical Society, 55(1), 150(2010), DOI: 10.4067/S0717-97072010000100035

23. A. H. Berger, andA. S. Bhown, Energy Procedia, 4, 562(2011), DOI: 10.1016/j.egypro.2011.01.089

[RJC-2056/2018] 